\title{
Integrating Websites in Second Language Teaching (SLT)
}

\author{
Ma. Olsa Pema \\ Ma.Ervin Xhinaku \\ English Lecturers, Faculty of Education and Philology \\ "Fan S. Noli" University, Korca, Albania \\ olsa.pema@yahoo.com, exhinaku@yahoo.com
}

\section{Doi:10.5901/mjss.2013.v4n11p577}

\begin{abstract}
This study aims to explore the nature of websites and their practical integration in a specially conceived English class - a radically new approach in the context of Albanian teaching traditions. The comparative analysis between two classes based on a broad range of data on the relative merits of traditional and innovative teaching methods leads to the conclusion that websites serve as a catalyst in the process of acquiring the various language skills. They are particularly helpful in integrating these skills as organic parts of a solid linguistic competence and contextualizing them in the ever-broader framework of intercultural communication - a distinctive feature of contemporary global society. Notwithstanding the drawbacks and difficulties that attend the application of web-based methods in SLT, the resulting advantages are so great as to constitute a paradigmatic shift in teaching practice and a qualitative leap forward in the promotion of autonomous and content-based learning.
\end{abstract}

Keywords: integration, authentic, linguistic competence, intercultural competence.

\section{Introduction - Websites and Their Role in SLT}

The digital age carries with it a tremendous potential for helping foreign language students and teachers by supplying them with an inexhaustible fountain of knowledge and a rich variety of methods that can be utilized during the teachinglearning process. Since we have opted for depth rather than comprehensiveness in a study of prefixed length, our analysis has focused exclusively on websites as one of the most popular tools the internet has to offers to SLT. A further stimulus for writing about websites and their potential in facilitating the acquisition of foreign languages is the fact that, though they constitute an ideal first step in trying to integrate the internet technology in the teaching process, their employment in Albanian schools remains pretty much an exceptional practice.

Among the advantages attending the use of websites in SLT, firstly, we would recognize (Dudeney \& Hockly, 2007) a fundamental characteristic that the technology required for working on the net is relatively simple and the risk of being let down by technical problems is very low when compared to other technology-based procedures like videoconferences, etc. Secondly, one can work with websites even in the absence of constant internet connection by saving copies of websites in the computer or printing them for future use. Web-pages can be used in class in the form of written materials; when there is only one computer in the classroom, they can be made visually accessible by the use of a projector or interactive smart board; ideally one can work with websites in a laboratory where computers are connected in a network. It is important that both teachers and students interpret the employment of internet tools in the foreign language classroom as an integral part of the teaching/learning process rather than an adventitious activity only extrinsically related to the study programme.

Internet sources related to language learning are very numerous and varied, though not all of them can be deemed sufficiently reliable to serve as an aid in the teaching of foreign languages. This is why the ability to critically assess the sites that can be used in SLT is of paramount importance for both teachers and students. A teacher's ability in this context entails the capacity to find valuable sources in a short time and, later, to use the researched material according to a well-organised lesson plan. The students, for their part, should respond by fulfilling their tasks on the web, showing, thus, that Internet technology serves as a catalyst, not a hindrance to the teaching/learning process.

In order to come up with a valuable final product we need to guide our search for websites by following a number of selective criteria. Some of the criteria highlighted by the literature (Dudeney \& Hockly, 2007) on the subject are: 
Accuracy - this is related to the authority behind the website. Is the author an expert of the subject or not? (The author's qualifications and professional experience need to be checked up to ascertain his expertise.) Are the contents of the "page" factually accurate and reliable? (Cross-references to other authoritative websites and/or encyclopaedias are needed to find this out.)

Currency - how up-to-date the information in the website is.

Content - is the site attractive, stimulating and easily accessible? The answers to this question need to take into account the students' own perspective.

Functionality - does the site run smoothly or is its exploration hampered by technical problems? The sound quality and the time it takes to download materials should also be checked for assessment (a short video that requires twenty minutes to download would be useless for the limited time-span of a single class).

Thus, the best way to approach the conduct of a web-based foreign language class is by careful planning and due consideration of all relevant factors and eventualities.

\section{Structural Description of a Web-Based and a Traditional Foreign Language Class}

In order to compare the role of websites with that of traditional teaching tools (texts, tape recorders, etc) in a foreign language class we planned and conducted an English class on Text Analysis with the first year students of English in the University of Korca. 24 students, chosen to represent the typical foreign language class, were divided into two equal groups of $12 .{ }^{1}$ The students of group A worked primarily on websites and the worksheets created for the occasion. Those of group $B$ followed the traditional procedure of listening to a tape recorder guided by the instructions given in the text. The basic objectives of this English class are:

- To develop the students' listening skills by exposing them to a discussion on the topic of fame and artistic careers.

- To expand and consolidate their vocabulary on the topic of art and entertainment.

- To aid the parallel development of the students' speaking, writing skills while expanding their cultural horizon about the target topic.

- To consolidate:

- interviewing techniques and communicative skills involved in social interaction

- the various structures of asking questions and giving answers in English

- the various ways of reacting and responding to new information.

Tools for the web-based class: computers linked to the internet (1 computer for two students), blackboard, worksheets. Tools for the traditional class: text, tape recorder, blackboard.

Time: 70 minutes

\subsection{Teaching through websites - model analysis ${ }^{2}$}

Topic: The Price of Fame - An Interview with a Film Star

Evocation (10 minutes): The topic is presented by asking students to express their opinions on their favourite movie stars and their famous roles. A relatively simple class discussion is sufficient for this stage; meanwhile the students are motivated to extend their thoughts on related facts and ideas like favourite films, latest productions, general tastes, etc. The main objective of this stage, besides serving to motivate the students for the foreign language class, is to evoke the use of structures commonly employed when asking questions in English and of such words and phrases that fall under the cultural concept of "fame" and "artistic career". The brainstormed words, phrases and structures (talent acting, publicly adored, producer, addicted to fame, press conference, a high public profile, celebrities, privacy invasion, to remain in the public eye, romance, thriller, screen, scene, plot, director, ending, audition) are put down on the blackboard.

Work on the web (35 minutes): The students are asked to visit the website where interviews with famous actors can be downloaded. In pairs they listen to a favourite actor of their own choice (there is a wide range of choices for the students). None of the interviews can be transcribed in captions.

${ }^{1}$ The students were divided in such a way as to balance the two groups in their representation of the different academic levels.

${ }^{2}$ The listening materials that were used for the web-based class can be found in the following site http://bbc.co.uk/radio4/collections /film-interviews 
The students should keep notes of the key issues discussed in the interviews. They should also concentrate on the organisational structure of the interview - the beginning of the interaction and the way it proceeds till the end. The requirements for these tasks are pointed out in detail in worksheets which are handed out to the students.

Post-listening activities (25 minutes): As the interview ends, all the students fill out their worksheets. Each student is given the opportunity to report on the contents of his/her interview. They highlight the new information they learned and talk on what they would like to have found in the interview that wasn't there. The key words and expressions of the interview are added to the concept tree on the blackboard (starring, image, Oscar Nomination, rehearsal, a volcanic role, a breakthrough, compromise, a hero...) resulting in an interrelated network of words and structures belonging to the beginning, the middle section and the ending of the interview.

Developing the skills needed to engage in a topical conversation with a native speaker of English requires time and effort. As a means to facilitate this process the students are asked to focus on the key structures used by the two interlocutors to build up the interview. The structures are written down on the blackboard and analysed with the whole class. Finally we proceed with the "follow up" stage, whereby the students in pairs improvise an interview which is then acted out. The aim is to use the students' feedback as a means of enhancing their speaking and writing skills.

\subsection{Teaching in the traditional way - model analysis}

Topic: The Price of Fame - An Interview with a psychologist and a rock star manager

Evocation (10 minutes): Both the form and the contents of this stage are almost identical for the two classes. The only difference concerns the use of the textbook in the traditional class instead of the worksheets prepared by the teacher for the web-based class. The text (Acklam \& Burgess, 2000) contains a number of questions which are related to some photos of famous actors. The students discuss the questions and the photos. Simultaneously the teacher uses the blackboard to write down the key words and structures that come up from the students' free discussion.

As an introduction (pre-listening task) to the interview of a rock star manager and a psychologist on the topic of fame the students are given guidelines on the notes they should take when they listen to the interview. They are also referred to a set of statements on the contents of the interview which they are going to mark as right or wrong after the listening task.

Listening task (30 minutes): All the students of the class listen to the same material under the teacher's guidance. The tape is played twice over to help the students catch what they missed in their first listening attempt. They keep notes, which later, in pairs, they use to formulate their answers.

Post-listening tasks (30 minutes)

a. The students discuss about the issues raised in the interview

b. The answers to the exercise from the text (statements that have to be marked as True or False) are examined in order to assess the degree of comprehension that has been attained by the students.

c. The students discuss on the language structures used in the introduction, the main body and the conclusion to the interview. These structures are noted down on the blackboard.

d. The students discuss on the key words (the vocabulary related to the topic of fame and artistic careers) of the interview, which are written down on the blackboard as an expansion of the concept tree that was first sketched out during the evocation.

Follow up: The students are asked to work in pairs in order to create their own interviews with famous persons. The interviews are then acted out in the classroom.

\section{A comparative Analysis of the Web-Based and the Traditional Class}

After the end of both classes a comprehensive analysis was carried out in order to assess the degree of success that was attained in the accomplishment of the objectives. More importantly, the analysis tries to account for the different factors that explain the respective advantages and drawbacks of the two classes. The facts and arguments that follow are organised in several lines of inquiry according to the different objectives that were set for the teaching class. The material used for the analysis comes from the extensive notes that I kept on all aspects of the two classes, from an evaluation of the students' written work and from the opinions they themselves gave when asked about the two classes.

Objective 1: Enhancing listening skills in the context of an interview on the career of a film star

The level of attainment for this major objective turns out to be higher for the web-based class. This conclusion is borne out by several indicators which show the difference in the students' feedback during the post-listening tasks. Thus, 
the greater comprehensiveness of the summaries (spoken and written) made by the students of the web-based class, the higher frequency with which they made use of the key structures and vocabulary of the material and the more active participation in the post-listening discussions all attest a more successful approach in attaining our objective.

The question that these results inescapably raise is: which are the factors that explain the advantages of using websites over more traditional teaching tools in fostering the students' listening skills? To find an answer to this query we need to pay attention to the way that students relate themselves to the new information when its source is a website. As our two classes show web-based activities contain the possibility of choice which is absent from more traditional procedures (in the web-based class every pair of students could choose its own interview; in the traditional class all the students had to listen to one and the same recorded interview). The initial act of choice is very important for the success of the listening class because by "personalizing" the interview the students feel more motivated for attentive listening and, consequently, better prepared to carry out the rest of their tasks. In fact, after the classes had ended the students were asked about their level of motivation. Their answers were in full accord with the above statements - on a scale from 1 to 4 , where 1 signifies the lowest and 4 the highest level of motivation, the mean choice for the students of the web-based class was 3 , for the students of the traditional class it was 2.3

Secondly, the website provided students with authentic rather than imaginary conversations serving a didactic purpose as was the case with the material recorded in the audiotape. As the students themselves confirmed the authenticity of the communication, by stimulating their interest on the contents of the interviews served also the function of increasing their concentration on the language structures that the interlocutors used.

Thirdly, the students who listened to the interviews from the website reported that they felt in charge of the process, since every pair of students had chosen its own interview which they could speed up or replay as they saw fit without the mediation of the teacher. Furthermore, the students' motivation and level of comprehension were markedly increased because of their cooperation in groups of two, whereby the students mutually stimulate and help each-other in fulfilling the assigned tasks. The above reasons explain the difference in the degree of actual comprehension, for listening texts of the same level of difficulty, exhibited by students of the two classes: on a scale from 1 to 4 , where 1 indicates the lowest and 4 the highest level of comprehensibility, the students of the web-based class chose 3 on the average, while those of the traditional class chose 2.

In the traditional class the students have no choice but to follow the teacher's handling of the tape recorder, who, on his part, has to treat the whole class as a homogenous unit without being able to respond to the needs of individual students for replaying the material, pausing to keep notes, etc. When asked whether they would prefer to manage the listening material themselves by having a free hand in using the website or to follow the teacher's management, $75 \%$ of the students chose the first option as the one that guarantees a high level of autonomy, while $25 \%$ chose the second, arguing that they would rather rely on the teacher's experience than risk failing to operate the website properly. Thus, it has to be pointed out that from a technical point of view the great majority of students have no difficulty in using websites as a basis for their listening tasks.

Many students of the traditional class complained about the noise in the classroom and the clarity of sound issuing from the tape recorder. Such hindrances to the successful understanding of the listening text were absent from the webbased class. Our experience has shown, however, that despite the disadvantages mentioned above, the traditional tools used in listening classes carry an important advantage over their net-based counterparts in that the listening materials associated with them, being specially prepared to serve the teaching process, are better suited to the students' level of English than the authentic listening materials found in websites. For this reason the teacher in the web-based class carries a high responsibility for addressing the students to the right sort of materials among the infinite variety of the web.

Objectives 2-3: Expanding the vocabulary related to the topic of artistic careers and making use of the structures and techniques involved in organising an interview, asking different types of questions and responding to new information.

The great variety of materials that a web-based listening class presents to the students makes it particularly successful in attaining the objective of increasing the corpus of their knowledge on the vocabulary and structures related to the topic under consideration. In our web-based class the students listened to six different interviews, each of which contained different special structures and made use of various techniques which the students were directed to concentrate upon (23 lexical units and 20 special structures used in the various stages of the interviews for the webbased class, as compared to 9 key lexical units and 7 such structures for the traditional class).

${ }^{3}$ Generally speaking, the students experience difficulties when listening to native speakers of English. This is in fact a typical problem for Albanian students of English - perhaps the result of their insufficient contact with authentic sources of English. 
Furthermore, not only does the web-based class present the students with a broader range of linguistic information, but due to its special reliance on each student's personal involvement in the teaching process, it also facilitates the assimilation of the information by all the students in the class (each student has a more personal grasp on the new words and structures that he has himself explored than in the case with the more passive attitude conditioned by more traditional tools like the tape recorder). The results of the follow up stage served to confirm the above analysis. In particular, the students of the web-based class did better in their writing tasks (the interviews composed by the students), as evidenced by the richer vocabulary and the greater accuracy in the employment of special structures learned from the interviews. Table 1 presents the results of this comparison between the two classes in quantitative terms:

Table 1.

\begin{tabular}{|l|c|c|}
\hline \multicolumn{1}{|c|}{ Language use for each student } & Web-based class & Traditional class \\
\hline Number of key lexical units used & $8-12$ & $5-8$ \\
\hline Number of special structures used & $8-11$ & $5-6$ \\
\hline Mean number of mistakes in the use of key lexical items & 2 & 2 \\
\hline Mean number of mistakes in the use of special structures & 2 & 2 \\
\hline
\end{tabular}

The figures in the table indicate quite clearly that, compared to the traditional class, the students in a web-based listening class are able to assimilate a richer corpus of special words and structures with an increased accuracy of usage (the number of mistakes is proportionally lower for the web-based class).

Objective 4: Fostering the development and integration of speaking and writing skills.

Even though our web-based class was mainly focused on listening activities, it proved very successful in promoting the other language skills (speaking and writing). As already mentioned, the use of websites stimulates the active participation of every student in the class. It is this heightened sense of interest and responsibility that explains the better quality of spoken and written English resulting from the accomplishment of post-listening tasks in the web-based class.

The promotion of learner's autonomy which results when every pair of students listens to the interview of their choice makes for a broader scope in the acquisition of key special words and structures. More specifically the advantages of the web-based class in helping the development of speaking and writing skills could be described as follows.

First, almost all the students of the web-based class were given the opportunity to report (verbally) on some of the information they had listened to. Since every pair of students had chosen its own material the amount of repetition was inconsiderable. In the traditional class all the students had to listen to the same recorded interview, which means that it took only 2 or 3 reports to fully cover the whole range of the material. Needless to say, the greater number of spoken reports in the web-based class can also be described as greater opportunities for the students to improve on their speaking skills. The higher level of participation in the post-listening tasks for the students of the web-based class is also shown by the fact that all of them (100\%) took an active part in creating their own interviews. This was not the case with the students of the traditional class: only 9 of them (75\%) were active in creating interviews, the remaining three simply did not make any contribution.

Second, the reports of the students of the web-based class, which were based on a more student-centred approach to the listening process, were both lexically richer and grammatically more correct in their use of special words and structures. The same can be said regarding the interviews created by the students in the post-listening stage of the class. Besides making use of a greater number of special newly learned structures, the students of the web-based class made, on average, only 1 mistake for every 4-5 structures; the respective results for the students of the traditional class were 1 mistake for every 3-4 structures. 4

Third, the notes kept by the students during the listening task were more extensive and better organised for the participants in the web-based class. Even the number of students that managed to keep notes was not the same: in the web-based class all the 12 students kept notes (100\%); in the traditional class only 9 did (75\%).

${ }^{4}$ The small difference in the absolute number of mistakes made by the students of the two classes is explained by the fact that the students of the traditional class were exposed to fewer new grammatical and stylistic structures than the students of the web-based class. 
Table 2.

\begin{tabular}{|l|l|}
\hline Web-based class & Traditional class \\
\hline High quality notes 3 & High quality notes 2 \\
\hline Medium quality notes 6 & Medium quality notes 3 \\
\hline Low quality notes 3 & Low quality notes 4 \\
\hline No notes at all 0 & No notes at all 3 \\
\hline
\end{tabular}

As a commentary on the above table we should point out that it is the students of a relatively low level whose performance is more influenced by the different procedures employed in the two classes. The good students are better prepared to overcome the disadvantages and drawbacks associated with particular tools and instruments.

Similarly, all the students of the web-based class took part in creating their own interviews and acting them out in pairs during the post-listening stage. In the traditional class only 9 students (75\%) were able to accomplish this task (irrespective of the quality of the product), the remaining 3 simply did not get involved in the process. What these facts indicate is that web-based activities, helpful as they are for foreign language students of all academic levels, prove to be a particularly effective stimulus in promoting the language skills of students traditionally regarded as passive and aloof.

All the above facts and arguments point toward the conclusion that not only do web-based activities stimulate the progressive development of each of the basic language skills, but that they do this by integrating the various skills together in order to achieve a unified and well-rounded language product.

Objective 5: Developing students' intercultural competence in the field of art and artistic careers.

The intercultural dimension of the teaching of foreign languages has been acquiring increasing prominence for some time now. Shu - Mei Hung (2007) has emphasized that the rapid globalization and digitalization of our societies have gradually made changes to our educational methods and goals. In terms of culture instruction, the traditional method of transmitting static target-culture knowledge to learners has been questioned and an intercultural approach is emerging, which depicts culture as a dynamic, multiple and ongoing process and emphasizes the need to equip foreign language learners with the critical attitude and proper skills to cope with the limitless possibilities they can encounter in the culturally and linguistically diversified modern society.

The well-planned integration of web-based activities into our foreign language classes could serve as a major stimulus in the development of the students' intercultural competence. The advantages they bring in the attainment of this objective can be analysed, yet again, by a comparative analysis between our two classes.

The authenticity of the interviews downloaded from the website, the reality of the characters and the sense of immediacy created by the students' own management of the listening process increased their interest in and concentration on the source material. As they reported later, the students came out of the classroom with an enlivened curiosity for some of the cultural issues touched upon in the interviews. They were very eager to give their impressions on the interviews. As one of the students put it, they "had not only listened but lived through an emotional and intellectual experience." 8 of the students expressed the wish to pursue the open-ended discussions of the interviews through further exploration in other web-based classes.

What interested the students beyond the mere recounting of concrete facts and basic information was the general socio-cultural context that made itself felt in the whole tenor of the argument, the system of values which they could identify in the narratives of the stars' successful careers. Self-reliance, the determination to follow one's vocation regardless of difficulties, hard work, the spirit of competition, respect for the individual's worth and sense of dignity, are some of the values, commonly associated with the culture of English-speaking peoples, that the students found reflected in the interviews. In addition to expanding the students' factual knowledge, the sheer variety of experiences related in the interviews, readily accessible on the web at any time and place, should make the students think and reflect on the diversity of cultural traditions, life styles and modes of thought in a pluricultural modern global society.

Compared to the interviews used in the web-based class the recorded material from the traditional class, though well-adapted to serve the purposes of intercultural communication, was found less culturally exciting (the students' comments on the recorded material exhibited a lower degree of aroused interest and personal commitment).

\section{Conclusions and Recommendations}

The comparative analysis between the web-based and the traditional class showed that the integrated use of web-sites brings several advantages to the teaching of foreign languages. First, it makes for a faster and more effective development of listening skills by increasing the students' motivation and sense of active participation through the rich 
diversity of choice and the authenticity of the source materials. Second, it opens up a wide domain for the successful assimilation of special words and grammatical structures. The greater availability of information, the closer intimacy of contact with the original sources and the higher level of active involvement in the whole process have a catalytic effect on the students' learning abilities. Third, the use of web-sites as a tool for teaching foreign languages enhances the development of speaking and writing skills for essentially the same reason of stimulating an increased sense of participation and cooperation. Fourth, websites open up a wide horizon for students of foreign languages, aiding in their cultivation as broad-minded citizens of the world with the intercultural competence to feel themselves decent members of a global community of peoples.

A very important related issue that has to be addressed in this context is that of the role of teachers in the two different types of classes and of their perceptions on the two alternative methodologies. The question of the cost of employing internet tools or traditional ones, on both teachers and students, is likewise both very relevant and important in our context.

As our experience indicates the type of reaction teachers make to the challenge of integrating the tools of the internet in their foreign language classes varies in accordance with some key factors. It is almost self-evident that a teacher's self-confidence is dependent on his/her degree of familiarity with the teaching context (students, methods, tools, materials, etc). Thus it is no surprise that many teachers feel more at home in a traditional class, especially when not only the technical handling of the new tools, but the contents of the materials themselves (in our case the different interviews the students can choose from the website) contain an element of novelty that is absent from the familiar procedures of the traditional class.

In addition, the time-consuming preparations that a well-planned web-based class requires (a suitable website, thinking out tasks on materials that, in themselves, are not intended for teaching purposes or creating worksheets in the absence of the text) might prove to feel too much of a burden for teachers already working hard to fulfil their regular duties.

On the other hand a teacher's confidence is boosted when the feedback he receives from his students is evidence of a high level of motivation and a quick pace of assimilation on their part. As we argued at some length in our analysis of the web-based class, this is precisely what happens in a well-integrated web-based approach to the teaching of foreign languages. Moreover, the teacher by relying on the students' own technical operations assumes a very convenient vantage point from which he can better supervise the work of each student.

Said the above, conducting a successful net-based foreign language class, even one based on a relatively easyto-use tool like a website, remains a challenge not to be taken lightly. Several caveats should be called into attention, some of which have a particular relevance for Albanian teachers. We need only mention the frequency of technical problems that attend the use of the internet in Albanian schools and the relatively low level of electronic competence often found among Albanian teachers and students to emphasise the necessity for long-term plans and strategies that should be thought out and implemented by visionary master planners in order to smooth the way for individual teachers in their efforts to adapt themselves to a new educational paradigm.

\section{References}

Acklam R.\& Burgess S. (2000). First Certificate gold coursebook. England: Longman.

Blake, R. J. (2008). Brave new digital classroom - technology and foreign language learning. Washington D.C.: George Town University Press.

Dudeney D.\& Hockly N. (2007). How to teach English with technology. England: Longman.

Hung S. (2007, January 12). Intercultural communicative competence in telecollaborative foreign language learning. from https://www.llas.ac.uk/resources/paper/2687

Van Compernolle, Remi A. \& Williams L. (2009). (Re)situating the role(s) of new technologies in world-language teaching and learning. in Second language teaching and learning in the Net Generation. ed. Raquel Oxford and Jeffrey Oxford, Honolulu: National Foreign Language Resource Center, p. 9-23.

Warschauer, M. \& Whittaker P.F. (1997). The internet for English teaching: guidelines for teachers. TESL Reporter, 30,1, p.27-33.

Warschauer, M. \& Healy D. (1998). Computers and language learning: an overview, language teaching. Cambridge, 31, p. 57-71.

BBC - Radio 4. (n.d.). Retrieved from http://www.bbc.co.uk/radio4/collections 